https://doi.org/10.23913/ciba.v10i20.108

Artículos científicos

\title{
Diagnóstico de áreas degradadas de manglar y propuestas de restauración ecológica en el estado de Guerrero, México
}

Diagnosis of mangrove degraded areas and proposals for ecological restoration in the state of Guerrero, Mexico

Diagnóstico de áreas degradadas de mangue e propostas de restauração ecológica no estado de Guerrero, México

Benjamín Castillo-Elías

Universidad Autónoma de Guerrero, México bcastilloelias@gmail.com https://orcid.org/0000-0003-1487-5353

Herlinda Gervacio-Jiménez Universidad Autónoma de Guerrero, México lindagj09@gmail.com https://orcid.org/0000-0003-3037-9528 José Angel Vences-Martínez Universidad Autónoma de Guerrero, México vences_angel@hotmail.com https://orcid.org/0000-0003-3543-9657 
Revista Iberoamericana de las Ciencias Biológicas

y Agropecuarias

\section{Resumen}

El incremento de las actividades humanas ha cambiado la hidrología de sistemas estuarinos y lagunares de zonas costeras, lo que ha generado la degradación de bosques de manglar. Por tanto, el objetivo del presente trabajo fue identificar y documentar la degradación de un área de manglar con daños estructurales, para lo cual se diseñó una propuesta técnica metodológica para determinar los factores causantes de la degradación, incluyendo acciones de restauración ecológica por implementar en la zona afectada en el estero de Tila, municipio de Marquelia, Guerrero, México. Se utilizó la metodología cualitativa mediante la técnica de observación participante en la zona de manglar afectada y la toma de fotografías como técnica para recolección de evidencias cualitativas, así como entrevistas a representantes clave que intervinieron en el proceso de identificación de la problemática, planteando la propuesta técnica de restauración de la zona afectada. Se identificaron las especies Rhizophora mangle, Laguncularia racemosa y Conocarpus erectus afectadas en un área de 15 hectáreas de manglar. Se recomendó a la Comisión Nacional Forestal desarrollar acciones para la identificación de la causa de mortandad del manglar y aplicar técnicas de restauración. Se concluye que las recomendaciones y la propuesta metodológica para identificar la mortalidad de los manglares fueron parcialmente abordadas, pues existió escaso monitoreo en el proceso de restauración en el sitio y, en consecuencia, poca efectividad en el proceso de técnicas de ingeniería ecológica.

Palabras clave: gestión forestal, hidrología, humedal, ingeniería ecológica, zona costera.

\section{Abstract}

The increase in human activities has changed the hydrology of estuarine and lagoon systems in coastal areas, resulting in the degradation of mangrove forests. The objective was to identify and document the degradation of a mangrove area with structural damage, designing a methodological technical proposal to identify and determine the factors that cause degradation, including ecological restoration actions to be implemented in the affected area in the Tila estuary, Marquelia Municipality, Guerrero, Mexico. Qualitative methodology and participant observation techniques were used in the affected mangrove area, as well as the photographic technique for collecting qualitative evidence, and interviews with key representatives who intervened in the process of identifying the problem, proposing the technical proposal of restoration of the affected area. Species of Rhizophora mangle, Laguncularia racemosa and Conocarpus erectus affected in an 
area of 15 hectares of mangrove were identified. The National Forestry Commission was recommended to take action to identify the cause of mangrove mortality and to apply restoration techniques. It is concluded that the recommendations and methodological proposal to identify mangrove mortality were partially addressed, there was low monitoring of the site restoration process and consequently little effectiveness in the process of ecological engineering techniques.

Keywords: forest management, hydrology, wetland, ecological engineering, coastal zone.

\section{Resumo}

$\mathrm{O}$ aumento das atividades humanas mudou a hidrologia dos sistemas estuarinos e lagunares nas áreas costeiras, o que levou à degradação das florestas de mangue. Portanto, o objetivo deste trabalho foi identificar e documentar a degradação de uma área de manguezal com danos estruturais, para a qual foi elaborada uma proposta técnica metodológica para determinar os fatores causadores da degradação, incluindo ações de restauração ecológica a serem implementadas na área afetada no município. Estuário de Tila, município de Marquelia, Guerrero, México. A metodologia qualitativa foi utilizada através da técnica de observação participante na área de manguezal afetada e a realização de fotografias como técnica de coleta de evidências qualitativas, além de entrevistas com representantes-chave que intervieram no processo de identificação do problema, levantando a proposta técnica de restauração. da área afetada. As espécies afetadas Rhizophora mangle, Laguncularia racemosa e Conocarpus erectus foram identificadas em uma área de 15 hectares de manguezal. A Comissão Nacional de Florestas foi recomendada a desenvolver ações para identificar as causas da mortalidade dos manguezais e aplicar técnicas de restauração. Conclui-se que as recomendações e a proposta metodológica para identificar a mortalidade dos manguezais foram parcialmente atendidas, uma vez que houve pouco monitoramento no processo de restauração do local e, consequentemente, pouca eficácia no processo de técnicas de engenharia ecológica.

Palavras-chave: manejo florestal, hidrologia, pantanal, engenharia ecológica, zona costeira. Fecha recepción: Diciembre 2020 Fecha aceptación: Julio 2021 


\section{Revista Iberoamericana de las Ciencias Biológicas y Agropecuarias}

\section{Introducción}

Los ecosistemas de manglar (ubicados en áreas aledañas a litorales, lagunas costeras, desembocaduras de ríos, esteros y humedales) tienen gran importancia no solo por los diferentes beneficios que proporcionan en cuanto a estabilización y protección de las líneas costeras, área de refugio, alimentación y anidamiento de diversas especies de fauna acuática y terrestre (Calderón, Aburto y Ezcurra, 2009), sino también por su extensión, diversidad, composición, estructura maderable y valores ecológicos (Castillo, Gervacio y Bedolla, 2018). Los manglares, por tanto, son considerados ingenieros naturales que integran, mantienen y determinan su ambiente físico. Su resiliencia natural incluye soportar condiciones de salinidad, desecación, inundación y capacidad de sostenerse en sustratos inestables (Olguín, Hernández y Sánchez-Galván, 2007).

Sin embargo, el incremento en las actividades humanas ha cambiado los flujos hidrológicos de los sistemas estuarios y lagunares costeros, lo que ha generado altos niveles de degradación de los bosques de manglar en ciertas regiones (Comisión Nacional Forestal [Conafor], 2009, 2011).

Ahora bien, en el caso de los manglares, el término restauración es utilizado para referirse a cualquier proceso encaminado a reponer sus condiciones previas. De hecho, dependiendo del nivel de intervención aplicada, esta puede ser mediante una "restauración activa", que se refiere a la recuperación deliberada del sistema degradado, simulando la dinámica natural del ecosistema (sucesión natural) con la intervención de la mano del hombre, o a través de una "restauración natural o pasiva", que consiste en la reparación natural de algún sistema degradado con una nula o mínima intervención del hombre, siguiendo los principios básicos de la sucesión secundaria (Holl y Aide, 2011).

En este sentido, Teutli-Hernández, Herrera-Silveira, Cisneros de la Cruz y Román-Cuesta (2020) definen la restauración como una actividad deliberada que inicia o acelera la recuperación de un ecosistema con respecto a su salud, integridad y sostenibilidad; sin embargo, en su mayoría los proyectos de restauración han sido actividades encaminadas a la reforestación de plántulas de mangle, como prácticas obsoletas de "ensayo-error", sin considerar estrategias adecuadas de restauración que dependan de las condiciones iniciales y el escenario ambiental de referencia de cada sitio, lo que trae como consecuencia el fracaso de la restauración (Teutli-Hernández y HerreraSilveira, 2016; Teutli-Hernández et al., 2020).

Con frecuencia, el ecosistema que requiere restauración se ha degradado, dañado, transformado o destruido totalmente como resultado directo o indirecto de las actividades antropogénicas, así como, aunque en menor medida, por fenómenos naturales como incendios, 
inundaciones, tormentas o erupciones volcánicas (Moreno-Casasola y Peresbarbosa, 2006; Ochoa, 2010).

Las estrategias de conservación o restauración dependerán del nivel de degradación del área afectada (Comín, 2014); en el caso de los ecosistemas de manglar, se puede aplicar a todo el manglar o a algunas secciones, lo que podría suponer el empleo de medidas de conservación o de restauración (Lindig y Zambrano, 2007).

De acuerdo con la Society for Ecological Restoration [Ser] (2004), la Comisión Nacional Forestal y la Secretaría de Medio Ambiente y Recursos Naturales [Conafor-Semarnat] (2010), y Gann et al. (2019), se deberían considerar los pasos para seguir e instrumentar un proyecto de restauración ecológica, el cual puede ser dividido en tres etapas: planeación, instrumentación y monitoreo (Fig. 1).

Figura 1. Procedimiento general de restauración ecológica

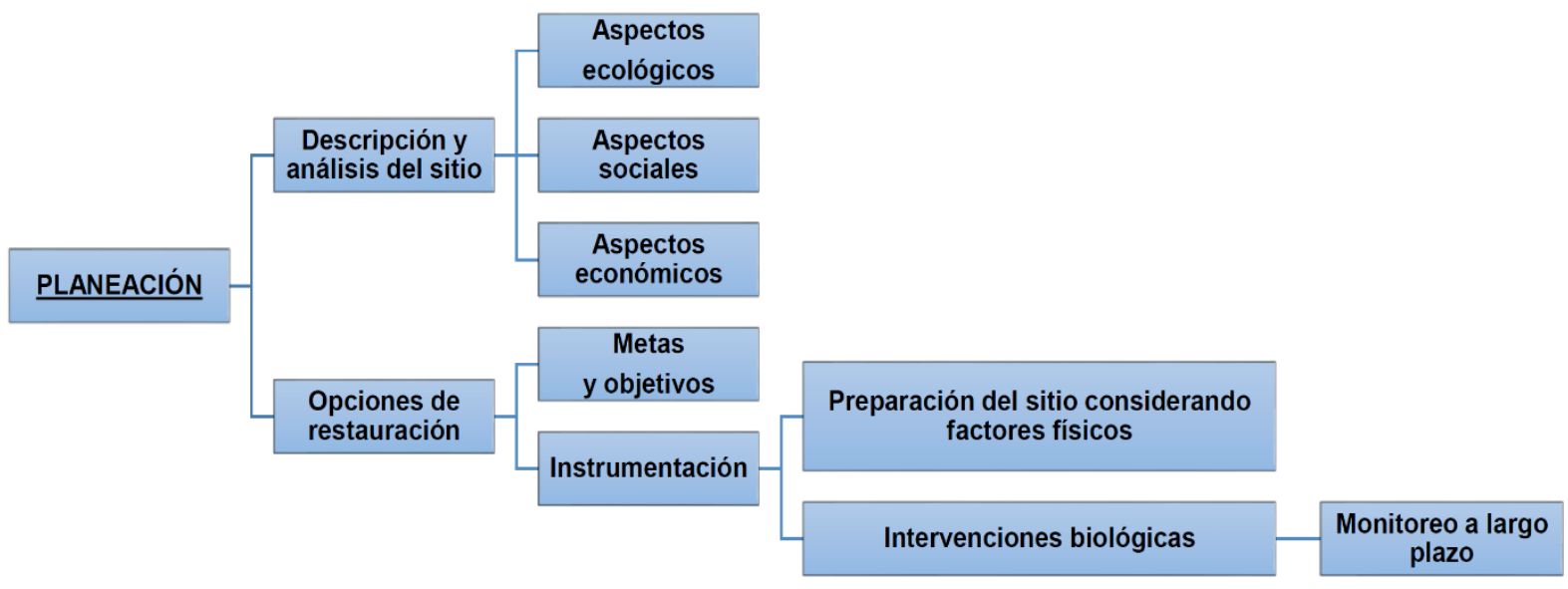

Fuente: Elaboración propia con datos de Lindig y Zambrano (2007)

En la etapa de planeación, se incluye el análisis del sitio y se evalúan los factores físicos, biológicos y sociales, considerando lo siguiente:

$\checkmark$ Evaluar el nivel de degradación.

$\checkmark$ Considerar como guía el paisaje circundante y su estado de conservación.

$\checkmark$ Aspectos sociales relacionados con la restauración incluyen el tipo de propiedad del predio (privado, comunal, estatal, entre otros). 
Revista Iberoamericana de las Ciencias Biológicas

y Agropecuarias

En la etapa de instrumentación e implementación, se llevan a cabo aquellas medidas que permitirán dirigir el sistema hacia el estado deseado, haciendo uso de distintas técnicas adecuadas de restauración.

En la etapa de monitoreo, la zona en proceso de restauración debe monitorearse para evaluar el desempeño en función de los objetivos planteados para cada etapa y de las metas que se desean alcanzar al final del proyecto y la evaluación de actividades de manejo y restauración. Durante esta fase existe la posibilidad de hacer modificaciones durante el proceso de restauración en caso de que, como resultado del monitoreo, se llegue a la conclusión de que el sistema está siguiendo una trayectoria no deseada, por lo que requiere ajustes en las etapas de metas y objetivos.

Por otro lado, Vanegas (2016) considera cinco líneas de acción para una eficiente restauración:

$\checkmark$ Ecología forense y el diagnóstico del manglar.

$\checkmark$ Definición de acciones de restauración.

$\checkmark$ Seguimiento de indicadores de éxito.

$\checkmark$ Socialización y participación pública.

$\checkmark$ Capacitación y transferencia de información.

Mientras que Lindig y Zambrano (2007), Teutli-Hernández y Herrera-Silveira (2016) y Teutli-Hernández et al. (2020) recomiendan una serie de atributos y variables susceptibles de ser monitoreados en un proyecto de restauración de manglar, que contemplen los siguientes indicadores:

Hidrología y topografía: Contempla el régimen de inundación, nivel del manto freático, flujo de agua a través del humedal, desarrollo de canales, cambios en el nivel de los humedales y sedimentación.

$>$ Calidad del agua: Considera la temperatura, oxígeno disuelto, salinidad, pH, atenuación de la luz, turbidez, estratificación de la columna de agua y concentraciones de nutrientes.

$>$ Suelo: Se enfoca en la calidad del sustrato, dinámica de nutrientes, contenido de agua (humedad del suelo), densidad, textura, salinidad, pH, potencial de óxido-reducción, contenido de materia orgánica y de carbono orgánico, nitrógeno y fósforo, tasas de descomposición, topografía y microtopografía.

Vegetación: Abarca aspectos de cobertura de la vegetación por especie, arquitectura de la vegetación, abundancia de especies (especies raras, amenazadas o invasoras), biomasa, productividad y volumen maderable. 
Revista Iberoamericana de las Ciencias Biológicas y Agropecuarias

$>$ Fauna: Se determina la identidad de las especies, abundancias, riqueza de especies y diversidad, estructuras poblacionales y tiempos de residencia (para el caso de animales que se desplazan, tiempo que ocupan en un hábitat).

Por otro lado, existen diferentes factores que favorecen la afectación de los manglares, como los siguientes:

Pobreza de los habitantes locales.

$>$ Falta de educación ambiental.

Desconocimiento de la importancia de los manglares.

$>$ Desconocimiento de las leyes sobre su protección y conservación.

$>$ Planificación inadecuada de actividades de desarrollo.

> Falta de un ordenamiento sistemático de las tierras de manglares.

> Escasa presencia de las autoridades para brindar protección a estos ecosistemas.

Actualmente, los manglares se mantienen protegidos por el siguiente extenso marco jurídico:

$>$ Ley General del Equilibrio Ecológico y la Protección al Ambiente (Lgeepa).

$>$ Ley General de Vida Silvestre.

$>$ Ley General de Desarrollo Forestal Sustentable (Lgdfs).

$>$ Reglamento de la Lgeepa en Materia de Evaluación del Impacto Ambiental

$>$ NOM-059-SEMARNAT-2010.

$>$ NOM-022-SEMARNAT-2003.

$>$ Código Penal Federal Mexicano en Materia de Delitos Ambientales.

$>$ Convención Internacional de Ramsar (2 de febrero de 1971).

$>$ Acuerdos y decretos internacionales aplicables.

Hasta el momento, en el estado de Guerrero no existen estudios exitosos de restauración ecológica en los sistemas de manglar, y solo se han realizado algunas actividades de reforestación. De hecho, las investigaciones se han enfocado en temáticas de taxonomía vegetal (Diego-Pérez y Fonseca, 2005), estudios de parámetros fisicoquímicos de las lagunas (Castillo-Elías, GervacioJiménez, Bedolla-Solano, García-Domínguez y Mendoza-Almazán, 2017; De la Lanza, AlcocerDurand, Moreno-Ruiz y Hernández-Pulido, 2008; Dimas, Ortega y Ortiz, 2018; Ferrara-Guerrero, Castellanos-Páez y Garza-Mouriño, 2007), relación de recursos pesqueros en zonas de manglar (Gil, Violante y Rojas, 2008), productividad de biomasa (Juárez, García, Olivier y Zeferino, 2019), fenología reproductiva (Tovilla y Orihuela, 2002), caracterización ambiental y componentes bióticos y abióticos (Villerías, Tello y García, 2016), composición estructural forestal y florística 
Revista Iberoamericana de las Ciencias Biológicas y Agropecuarias

en una zona de manglar (Castillo et al., 2018), presencia de plaga en manglares (Castillo-Elías y Gervacio-Jiménez, 2013), afectaciones del manglar por actividades antropogénicas (VencesMartínez et al., 2018, García-Domínguez et al., 2020) y planes de manejo comunitario sustentable de manglar (García-Domínguez et al., 2019).

Por tanto, el objetivo de la presente investigación fue identificar y documentar la degradación de un área de manglar con daños estructurales. Para ello, se diseñó una propuesta técnica metodológica para identificar y determinar los factores causantes de la degradación, incluyendo acciones de restauración ecológica para implementar en la zona afectada del estero de Tila, perteneciente al ejido de Barra de Tecoanapa, municipio de Marquelia, Guerrero.

\section{Materiales y métodos \\ Área de estudio}

El área de afectación de manglares se ubica en la proximidad del estero de Tila en las coordenadas geográficas $16^{\circ} 31^{\prime} 46,30^{\prime \prime} \mathrm{N}$ y 98 44' 47,62" O (Fig. 2), perteneciente al municipio de Marquelia, Guerrero.

Figura 2. Ubicación de la zona de manglar afectada

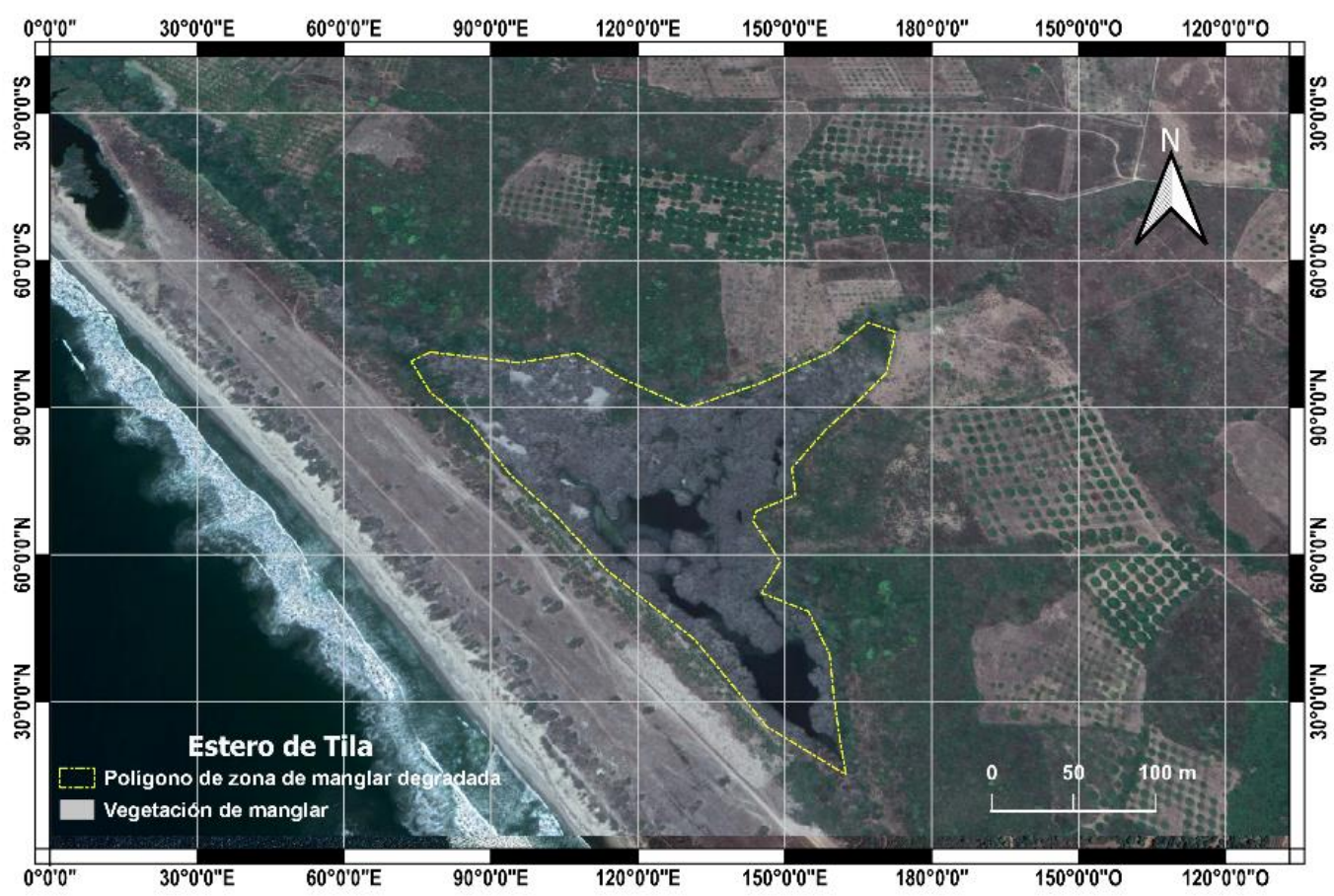

Fuente: Elaboración propia con software QGIS (2021) y datos de Google Earth Pro (2016)

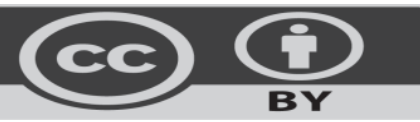




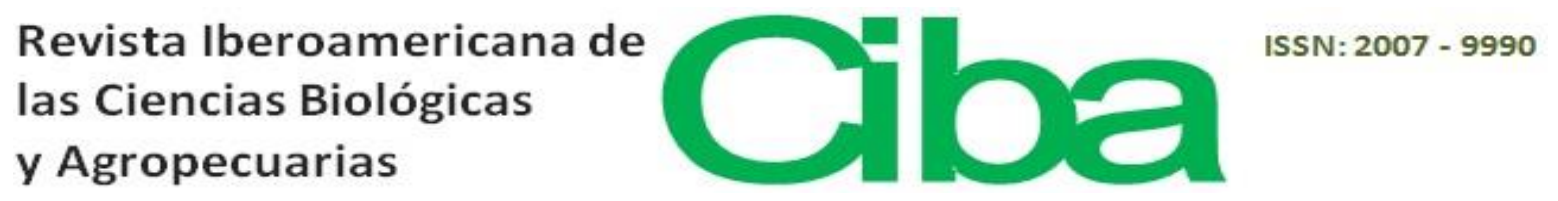

Su orografía característica es del tipo de relieve constituido por zonas semiplanas y planas, con alturas que oscilan entre 5 y $50 \mathrm{~m}$ s. n. m. Su hidrografía se representa por la presencia de los ríos Quetzala (río Grande), ubicado en la parte sureste, río Marquelia o San Luis, que corre sobre la parte poniente del área municipal, marcando el límite con los municipios de Copala y San Luis Acatlán. Existen otros arroyos de menor caudal, como Zayotlán, El Zapote, Tila, Arroyo Seco y El Guayabal.

El clima característico es de tipo cálido subhúmedo, con temperatura de $17^{\circ} \mathrm{C}$ en la época de invierno, que comprende los meses de diciembre y enero. La temperatura máxima, en mayo, alcanza los $36^{\circ} \mathrm{C}$, siendo los meses más calurosos los de primavera y verano, presentando lluvias con promedio anual de $1200 \mathrm{~mm}$. Las mayores precipitaciones comprenden los meses de junio a septiembre (Gobierno del Estado de Guerrero, 2015).

\section{Muestreo}

Se realizaron recorridos vía terrestre en el área de estudio a lo largo del margen del estero de Tila en la parte norte y sur. Para ello, se empleó la metodología cualitativa mediante un análisis exploratorio, inductivo y descriptivo (Monje, 2011), utilizando la técnica de observación participante (Gómez, 2012; Hernández-Sampieri, Fernández y Baptista, 2018; Taylor y Bogdan, 2000).

Se recolectaron evidencias cualitativas de los daños observados sobre la vegetación de manglar por medio de la técnica fotográfica (González, 2008) con la finalidad de tener insumos visuales de la afectación.

Se diseñó una propuesta técnica de restauración ecológica fundamentada en la metodología de ingeniería y ecología forense para la restauración de manglares citada por Mitsch y Jørgensen (2003), Lindig y Zambrano (2007), Teutli-Hernández y Herrera-Silveira (2016). Para el monitoreo de los parámetros fisicoquímicos del agua lagunar se consideraron la Norma Oficial Mexicana NOM-127-SSA1-1994 (Secretaría de Salud [Ssa], 1994) y los criterios ecológicos CE-CCA001/89 (Instituto Nacional de Ecología [Ine], 1989). El análisis microbiológico del agua lagunar se fundamentó en la NOM-127-SSA1-1994 (Secretaría de Salud [Ssa], 1994) y en el método de determinación de bacterias coliformes CCAYAC-M-004-2006 (Secretaría de Salud [Ssa], 2006); asimismo, se recomendó el análisis de suelo adjunto al ecosistema afectado contemplando los parámetros fisicoquímicos recomendados por Ruiz-Ochoa, Meléndez, Castellanos y Polanía (2006). 
Esta propuesta metodológica se presentó ante las autoridades ambientales en un foro forestal donde se encontraban presentes las autoridades ambientales y representantes de la comunidad de Barra de Tecoanapa, Guerrero, con la finalidad de ser implementada en la zona afectada de manglar del estero de Tila.

Se realizaron entrevistas a informantes clave que intervinieron en el proceso de identificación de la problemática, tales como representantes de la Procuraduría de Protección Ambiental del Estado de Guerrero (Propaeg), Procuraduría Federal de Protección al Ambiente (Profepa), Conafor y Ecología Municipal de Marquelia, Guerrero. Asimismo, se efectuaron recorridos in situ en la zona intervenida de manglares para verificar la situación actual del proceso de restauración ecológica.

\section{Resultados}

\section{Identificación de las problemáticas}

Durante junio de 2016, en coordinación con el personal de la Propaeg, Conafor y la Dirección de Ecología Municipal de Marquelia, se realizaron recorridos vía terrestre a lo largo del margen del estero de Tila en la parte norte y sur, respectivamente. Se recolectaron evidencias fotográficas principalmente de los daños sobre la vegetación de manglar con la finalidad de tener evidencias para la propuesta técnica de restauración ecológica e intervención inmediata.

Se detectó la afectación sobre una superficie aproximada de 15 hectáreas de manglar, que presentaba un fenómeno denominado manglares envejecidos (Fig. 3). 
Revista Iberoamericana de las Ciencias Biológicas y Agropecuarias

Figura 3. Mangles afectados (manglares envejecidos)

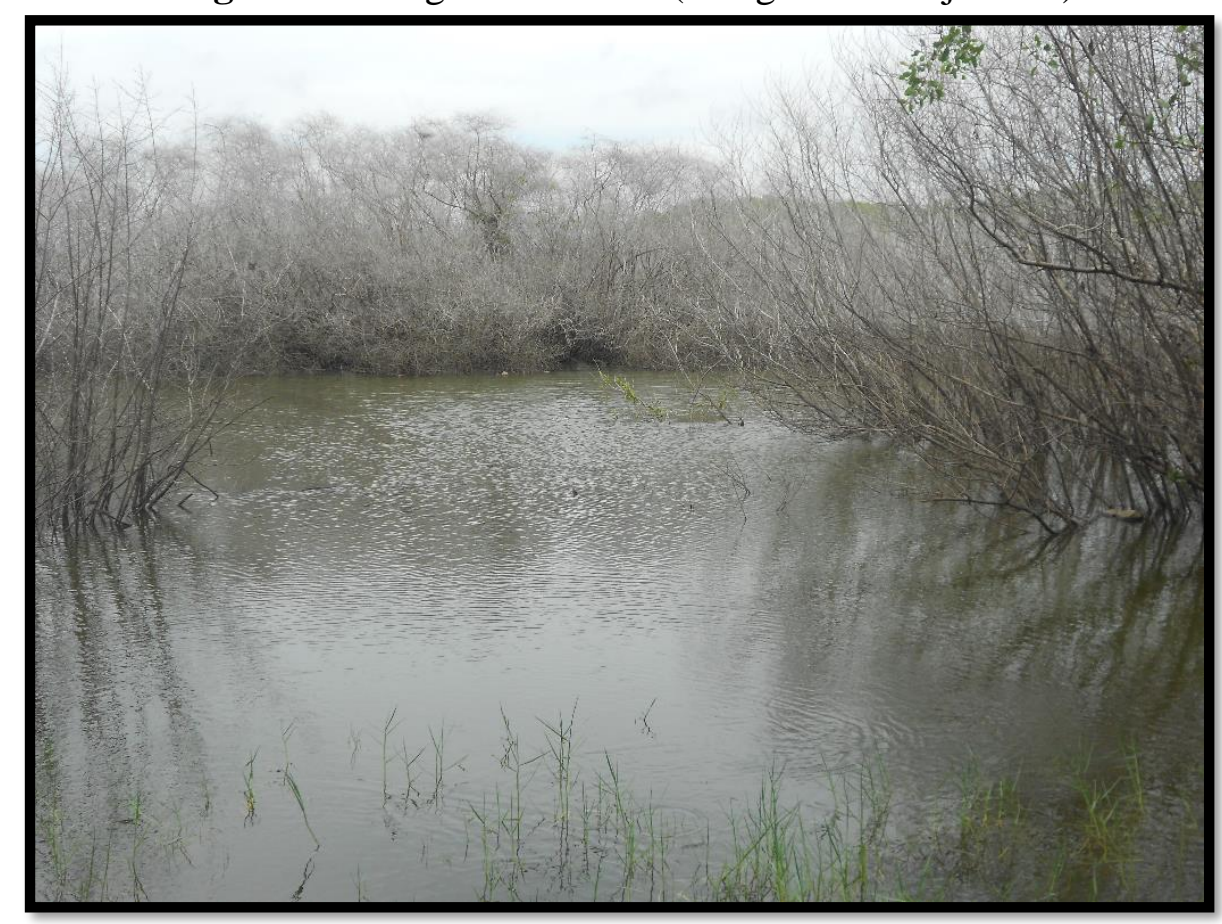

Fuente: Fotografía por Benjamín Castillo-Elías

Se identificó la afectación principalmente en las especies de mangle rojo (Rhizophora mangle), mangle blanco (Laguncularia racemosa) y mangle botoncillo (Conocarpus erectus), las cuales se encuentran enlistadas en la NOM-059-SEMARNAT-2010 (Secretaría de Medio Ambiente y Recursos Naturales [Semarnat], 2010), consideradas bajo un estatus de riesgo y bajo protección. No se detectaron daños para otras especies de flora de acompañamiento, con características de un bosque de manglar tipo ribereño.

Una vez realizado el recorrido en campo y recolectadas las evidencias, en septiembre de 2016 se participó en el foro estatal forestal con una investigación titulada Buenas prácticas para la conservación del agua y suelo, organizado por la Comisión Nacional Forestal (Conafor) con sede en Chilpancingo, Guerrero. Allí se presentaron los hallazgos del diagnóstico en la zona afectada del manglar, así como las recomendaciones y la propuesta técnica de restauración, que incluyó la metodología para implementarla en la zona degradada. 


\section{Propuestas y recomendaciones para la restauración}

Se recomendó considerar los indicadores de hidrología, topografía, calidad del sustrato y dinámica de nutrientes, calidad de agua, vegetación y fauna como medidas para intervenir en la zona de manglar e identificar la causa de mortandad. En concreto, se plantearon las siguientes acciones:

1) Convocar reuniones de trabajo entre los actores clave, como son la Secretaría de Medio Ambiente y Recursos Naturales (Semarnat), Procuraduría Federal de Protección al Ambiente (Profepa), Comisión Nacional del Agua (Conagua), Secretaría de Medio Ambiente y Recursos Naturales del Gobierno estatal de Guerrero (Semaren), Procuraduría de Protección Ambiental del Estado de Guerrero (Propaeg), Comisión Nacional Forestal (Conafor), Presidencia Municipal de Marquelia a través de la Dirección de Ecología Municipal, sector salud estatal y federal (Ssa), sector académico y autoridades ejidales de la comunidad, con la finalidad de tomar decisiones colegiadas sobre esta problemática.

2) Realizar el estudio de la calidad del agua seleccionando diferentes estaciones de muestreo del cuerpo del estero a través de la medición de los siguientes parámetros fisicoquímicos:

$\checkmark \mathrm{PO}_{4}{ }^{3-}$ (ortofosfatos).

$\checkmark \mathrm{NO}_{3}^{-}$(nitratos).

$\checkmark \mathrm{NO}_{2}^{-}$(Nitritos).

$\checkmark \mathrm{SO}_{4}{ }^{2-}$ (sulfatos).

$\checkmark$ OD (oxígeno disuelto).

$\checkmark$ SAAM (sustancias activas al azul de metileno).

$\checkmark \mathrm{C}_{6} \mathrm{H}_{6} \mathrm{O}$ (fenoles).

$\checkmark$ DBO (demanda bioquímica de oxigeno).

$\checkmark \mathrm{pH}$ (potencial de hidrógeno).

$\checkmark$ GyA (Grasas y Aceites).

$\checkmark$ SST (sólidos suspendidos totales).

$\checkmark$ PT (fósforo total).

$\checkmark$ NT (nitrógeno total).

$\checkmark \quad$ Salinidad (ppm, \%, PSU o UPS).

$\checkmark$ Conductividad eléctrica (CE).

$\checkmark$ Turbiedad (UTN).

$\checkmark \quad \mathrm{T}^{\circ} \mathrm{C}$ (temperatura). 
Del análisis de calidad del agua, en la tabla 1 se recomienda considerar nueve parámetros fisicoquímicos con sus respectivos valores de referencia (límites permisibles de calidad) de acuerdo con la Norma Oficial Mexicana NOM-127-SSA1-1994 (Secretaría de Salud [Ssa], 1994), criterios ecológicos CE-CCA-001/89 (Instituto Nacional de Ecología [Ine], 1989) y métodos de prueba correspondientes y aplicables a los cuerpos lagunares.

Tabla 1. Valores medios de indicadores físicoquímicos de calidad del agua y métodos analíticos

\begin{tabular}{|l|c|c|}
\hline \multicolumn{1}{|c|}{ Parámetro evaluado } & Método analítico de prueba & $\begin{array}{c}\text { Límite permisible de } \\
\text { cuantificación } *\end{array}$ \\
\hline Nitritos (como N) mg/L & Colorimétrico & 1,0 \\
\hline Sólidos totales mg/L & NMX-AA-034-SCFI-2001 & No aplica \\
\hline Oxígeno disuelto mg/L & NMX-AA-012-SCFI-2001 & $1 \mathrm{mg} / \mathrm{L}$ \\
\hline Grasas y aceites mg/L & NMX-AA-005-SCFI-2000 & No aplica \\
\hline $\begin{array}{l}\text { Salinidad \% o S (ppm o } \\
\text { UPS) }\end{array}$ & NMX-AA-073-SCFI-2001 & No aplica \\
\hline $\begin{array}{l}\text { Conductividad } \mu \mathrm{S} / \mathrm{cm} \text { a } \\
25^{\circ} \mathrm{C}\end{array}$ & NMX-AA-093-SCFI-2000 & No aplica \\
\hline Turbiedad UTN & NMX-AA-045-SCFI-2001 & 5,0 \\
\hline $\mathrm{pH}$ & NMX-AA-008-SCFI-2000 & $6,5-8,5$ \\
\hline Temperatura ${ }^{\circ} \mathrm{C}$ & in situ & No aplica \\
\hline
\end{tabular}

* De acuerdo con la NOM-127-SSA1-1994 (Secretaría de Salud [Ssa], 1994)

Fuente: Elaboración propia

Asimismo, se sugirió incluir en el análisis de calidad del agua la determinación de sustancias tóxicas (p. ej., metales pesados, plaguicidas y bacterias coliformes) debido a las evidencias de aplicación de fertilizantes y herbicidas encontradas en las huertas cercanas al lugar de la afectación. En este punto, para el análisis de los parámetros microbiológicos de coliformes totales (CT) y coliformes fecales (CF) se recomendó considerar la NOM-127-SSA1-1994 (Secretaría de Salud [Ssa], 1994) y el método de determinación de bacterias coliformes CCAYACM-004-2006 (Secretaría de Salud [Ssa], 2006) para definir la viabilidad del agua para recreación y consumo humano.

3) Considerar la topografía y el análisis de suelo adjunto al ecosistema afectado contemplando los parámetros correspondientes de acuerdo con Ruiz-Ochoa et al. (2006), determinando las propiedades edáficas (descripción del perfil del suelo) del manglar, salinidad $\left(\mathrm{mg} \mathrm{L}^{-1}\right)$, conductividad eléctrica $\mathrm{CE}\left(\mu \mathrm{S} \mathrm{cm}^{-1}\right)$, materia orgánica MO (\%) y pH (Tabla 2). 
Tabla 2. Métodos utilizados en la determinación de las propiedades edáficas del manglar

\begin{tabular}{|l|l|}
\hline \multicolumn{1}{|c|}{ Propiedad } & \multicolumn{1}{c|}{ Método } \\
\hline Humedad & Secado a $105^{\circ} \mathrm{C}$ hasta peso constante. \\
\hline Salinidad y CE & $\begin{array}{l}\text { Potenciómetro. Salinidad }\left(\mathrm{mg} \mathrm{L}^{-1}\right) \text { y conductividad eléctrica (tetra con } 325 \\
1 \mu \mathrm{S} \mathrm{cm}\end{array}$ \\
\hline MO & Calcinación a $550{ }^{\circ} \mathrm{C}$ en mufla. \\
\hline pH & $\begin{array}{l}\text { Potenciómetro. Multiparamétrico WTW P4 con el electrodos pH Sen Tix } \\
41-3(0-14) .\end{array}$ \\
\hline
\end{tabular}

Fuente: Ruiz-Ochoa et al. (2006)

4) Realizar un diagnóstico de todo el embalse del estero (cuenca) para identificar el comportamiento del flujo hidrológico y determinar acciones para restaurar las condiciones hidrológicas y la rehabilitación del ecosistema de manglar, ya sea por desazolve y/o apertura de canales.

5) Considerar la evaluación de la línea base a partir de seleccionar el bosque de referencia para tener el comparativo de la zona no perturbada y determinar el proceso de restauración ecológica asistida.

6) Rescatar las plántulas de mangle que se están desarrollando en el estero y que no se han afectado para evitar su muerte, así como recolección de semillas y esquejes en buenas condiciones para ser trasladas a un vivero temporal y tener propágulos para la restauración y forestación correspondiente.

7) Realizar el cálculo del volumen maderable de la madera muerta y su remoción como medida de saneamiento para la apertura de espacios y canales entre la vegetación muerta de manglar.

8) Identificar los sitios adecuados para restaurar y forestar.

9) Evaluar, monitorear y dar seguimiento al programa de restauración para medir los avances, resultados e indicadores de éxito, que permitirán realizar los ajustes correspondientes para evitar o minimizar un posible fracaso en la restauración ecológica.

En seguimiento a la propuesta metodológica anteriormente citada, en el mes de agosto de 2020 se realizaron entrevistas a funcionarios e informantes clave que participaron en la identificación de esa problemática de la zona de manglar para verificar si se atendió la propuesta planteada de restauración en el año 2016, donde mencionaron que en el año 2018, a través del programa de compensación ambiental por cambio de uso de suelo en terrenos forestales, financiado 
por Conafor-Semarnat, se intervino en la zona afectada de manglar participando personal de Conafor y algunos pobladores de la zona rural de Barra de Tecoanapa, Guerrero.

De acuerdo con la información recabada de las entrevistas, se buscó información oficial en las dependencias de gobierno (como Propaeg, Profepa, Conafor y Ecología Municipal de Marquelia, Guerrero), las cuales desconocían las acciones de restauración realizadas en el sitio afectado.

Por lo anterior, se realizó a través de imágenes aéreas el comparativo de la zona de manglar antes de la restauración del año 2016 (Fig. 4) y después de la restauración correspondiente al año 2020 (Fig. 5). Se observaron evidencias de intervención en el área afectada y se identificó que la cobertura forestal de manglar es escasa en el interior del estero después de dos años de haber intervenido dicho espacio.

Figura 4. Zona afectada antes de la restauración (junio 2016)

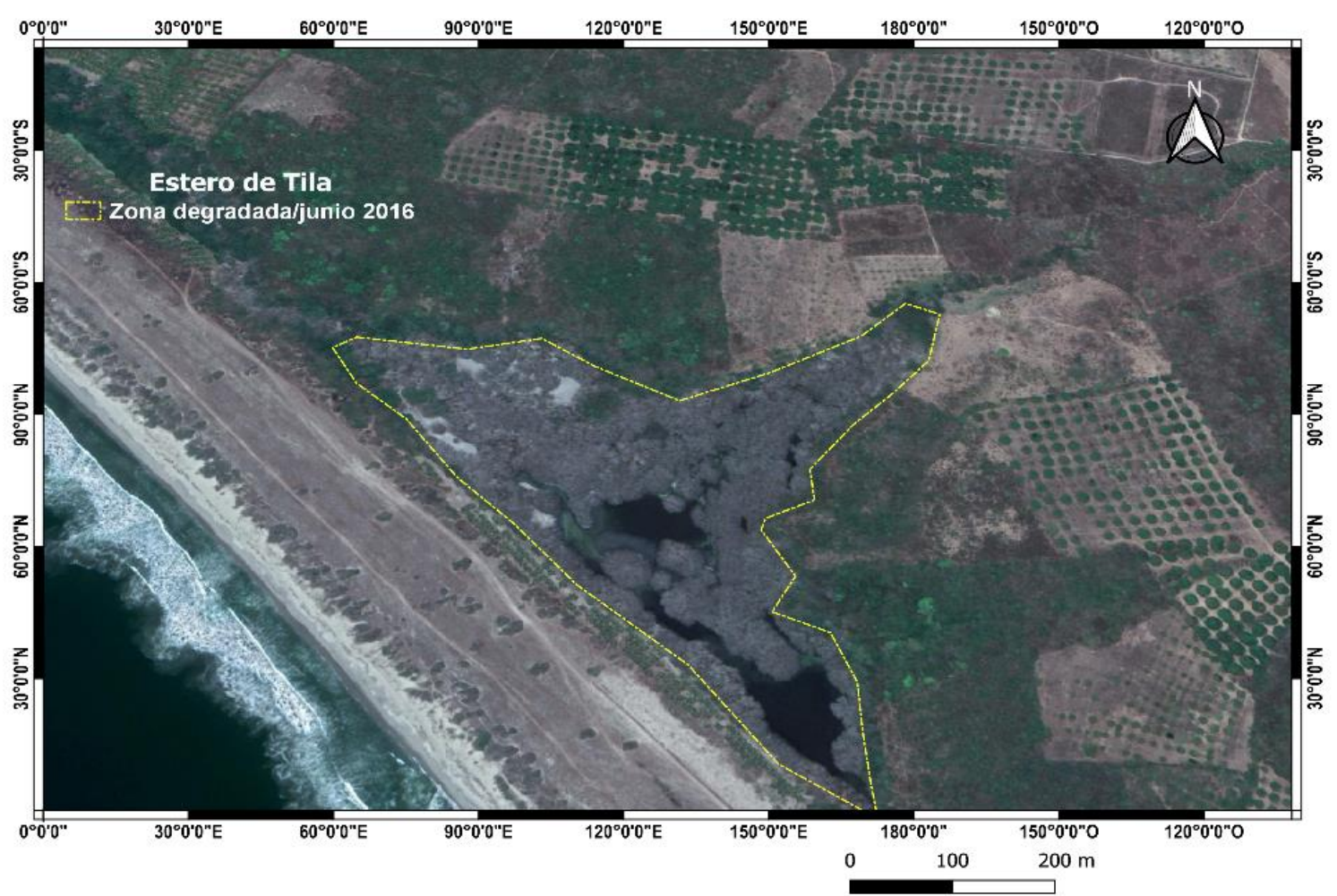

Fuente: Elaboración propia con software QGIS (2021) y datos de Google Earth Pro (2016) 
Revista Iberoamericana de las Ciencias Biológicas y Agropecuarias

Figura 5. Zona restaurada (agosto 2020)

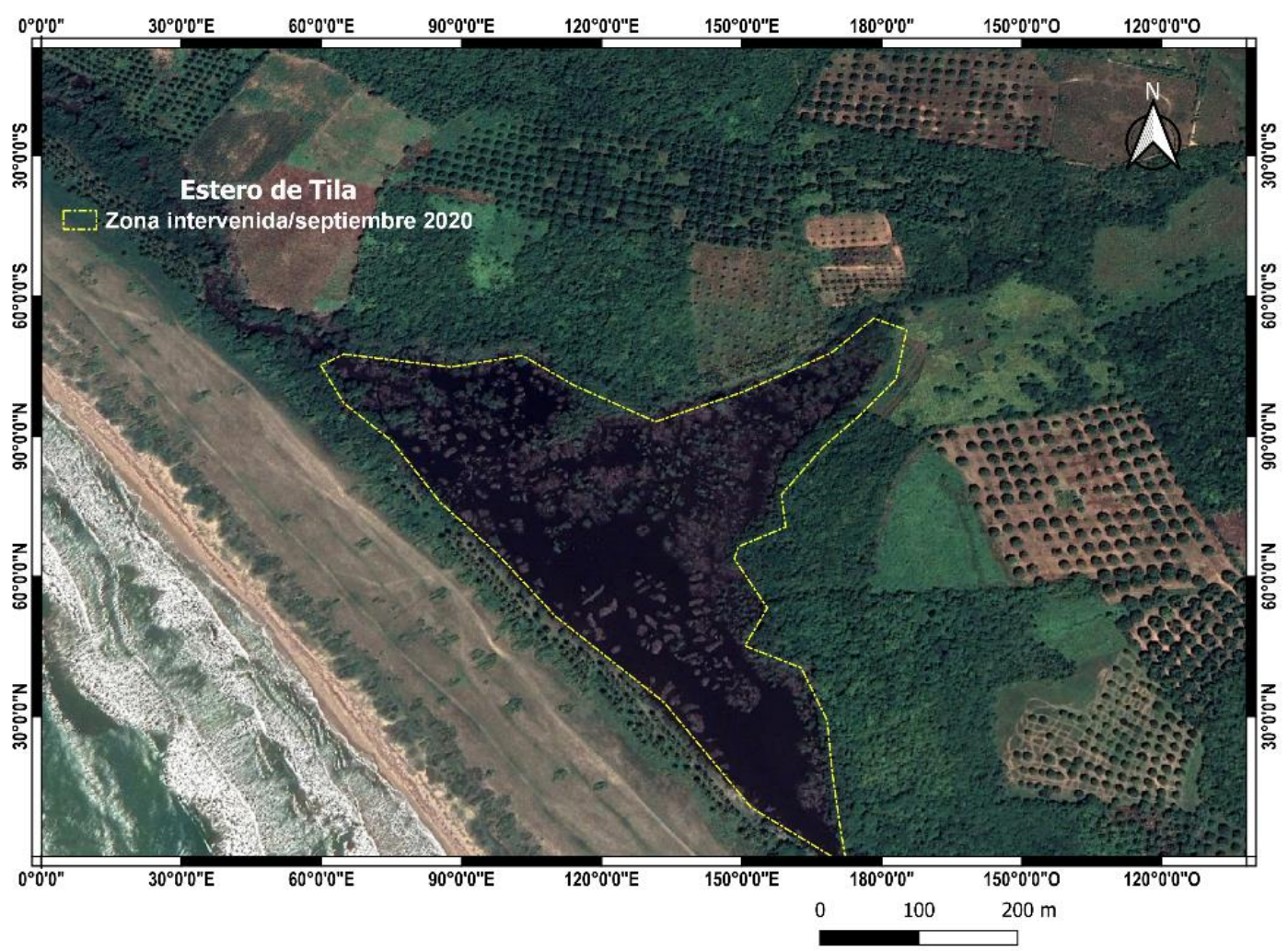

Fuente: Elaboración con software QGIS (2021) y datos de Google Earth Pro (2020)

\section{Verificación in situ de la zona intervenida}

De acuerdo con los resultados obtenidos en las entrevistas a los actores clave, en septiembre de 2020 se realizó un recorrido en el sitio intervenido con la finalidad de obtener información visual sobre las condiciones actuales de la zona de manglar. Allí se apreciaron el saneamiento de la materia vegetal muerta y la fluidez del cuerpo lagunar, así como las actividades de reforestación, principalmente sobre la periferia del estero, donde se observaron ejemplares de $L$. racemosa y $C$. erectus provenientes de una actividad de reforestación manual, algunos en buenas condiciones y otros dañados o muertos. No se detectaron evidencias de monitoreo recientes debido a que en el interior del cuerpo del estero se halló el nivel de marea muy alto; en ese momento no se apreciaron evidencias de técnicas de restauración por translocación de suelos como son los encamados, huacales, chinampas, entre otros (Fig. 6), lo que les permitiría a las plántulas o propágulos de mangle la supervivencia si se hubiese implementado correctamente la técnica metodológica de restauración propuesta inicialmente. Lo anterior confirmó que no se ha dado seguimiento, monitoreo y mantenimiento en el área restaurada. 
Revista Iberoamericana de las Ciencias Biológicas y Agropecuarias

Figura 6. Condición actual de la zona de manglar (septiembre de 2020)
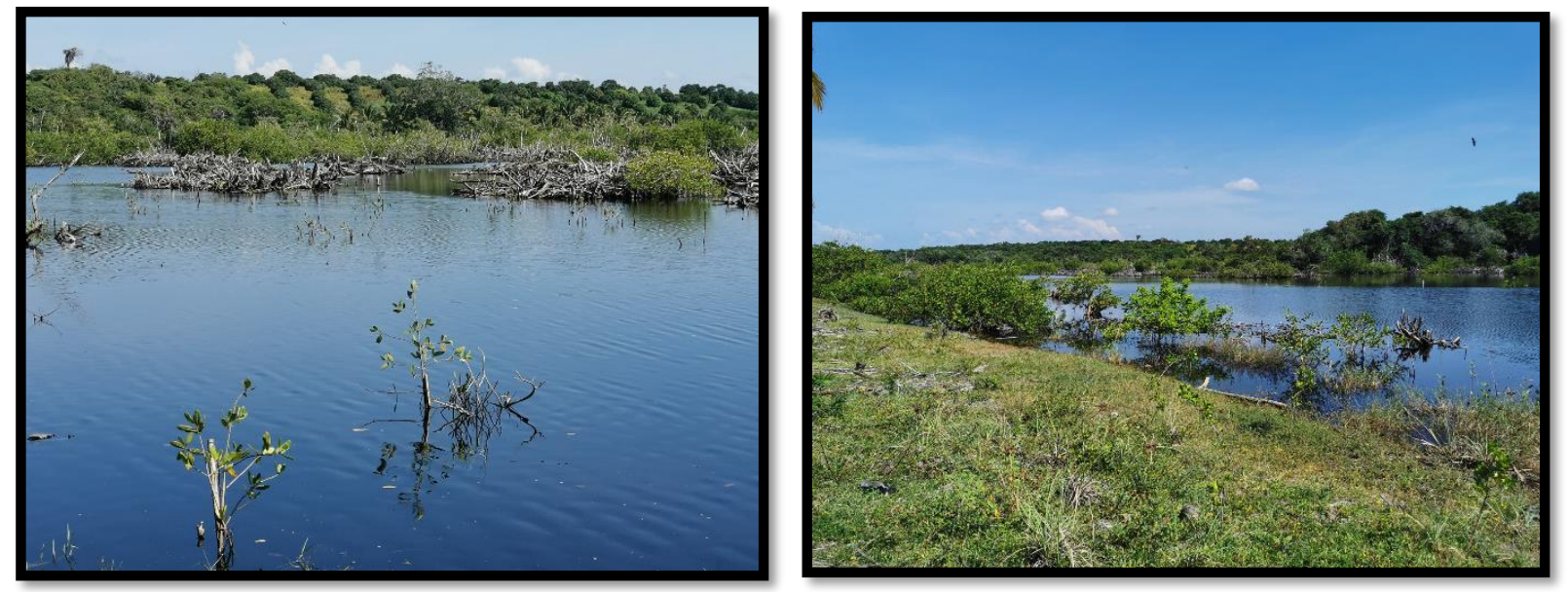

Fuente: Fotografías por Herlinda Gervacio Jiménez

\section{Discusión}

De acuerdo con los resultados obtenidos, se determinó que la sintomatología observada en la zona de estudio en el año 2016 presentaba el fenómeno denominado mangles envejecidos. De hecho, en estudios realizados en zonas de manglar, Castillo-Elías y Gervacio-Jiménez (2013) determinaron que son diversas actividades antropogénicas las causantes de este fenómeno, como la ganadería, la tala y la desecación (Castillo et al., 2018), vertimiento de aguas residuales o productos químicos que afectan al ecosistema acuático e impactan dramáticamente la zona de manglar por la contaminación de la calidad del agua lagunar (Castillo-Elías et al., 2017; Dimas et al., 2018), por la presencia de insectos plaga, los cuales (por condiciones de cambio climático) proliferan y afectan los bosques de manglar (Castillo-Elías y Gervacio-Jiménez, 2013), y por infestación de hongos patógenos, como la especie Cytospora rhizophoreae (Perdomo, Miniño, Rodríguez de Francisco y León, 2018). Esto ocasiona la muerte de semillas, retoños y la destrucción de las raíces aéreas de $R$. mangle, así como la falta de aporte e intercambio entre aguas continentales y agua oceánica para mantener equilibrada la concentración de salinidad y regular el hidroperiodo, como lo menciona Teutli-Hernández et al. (2020). Por eso, es necesario considerar el análisis de calidad de agua en la zona adjunta al manglar estudiado para determinar la causa del daño. 


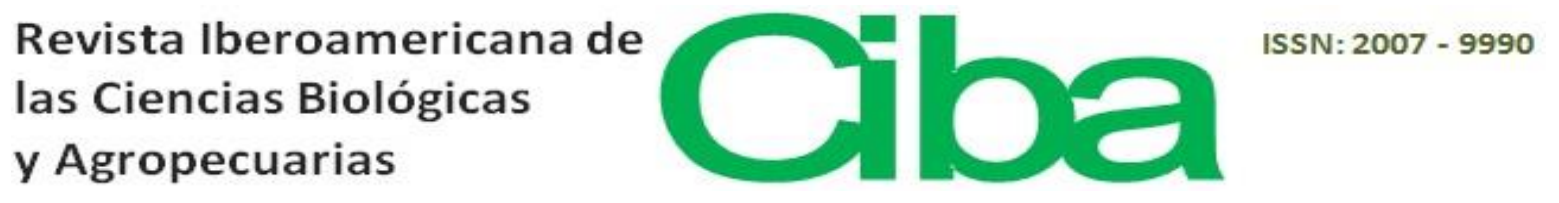

Durante el recorrido in situ en el año 2020, no se observó cobertura forestal de manglar que era representativa antes de la degradación, por lo que se determinó que la intervención de restauración realizada en 2018 no ha sido exitosa hasta el momento; de acuerdo con las evidencias cualitativas detectadas, hizo falta la implementación de un programa de monitoreo constante de actividades, tal como lo recomiendan Aguilar-Garavito y Ramírez (2015) y Evans y Guariguata (2016), quienes proponen el monitoreo para la medición de avances y resultados óptimos en los programas de restauración ecológica.

Asimismo, la Secretaría de Medio Ambiente, Recursos Naturales y Pesca y el Instituto Nacional de Ecología [Semarnap-Ine] (2000), así como la Comisión Nacional del Agua [Conagua] (2006) y Castillo-Elías et al. (2017) recomiendan que, para una intervención exitosa, el primer paso se debe enfocar en los estudios de la calidad del agua mediante el análisis de parámetros fisicoquímicos, pues esto permitirá diseñar la metodología adecuada para la intervención en el sitio afectado, lo que evidentemente no se llevó a cabo durante la intervención de restauración en el año 2018.

Se detectó también que no existió un correcto saneamiento en la zona afectada debido a que durante el periodo de identificación del daño se observó gran cantidad de madera muerta de manglar, la cual debió ser aprovechada como leña y/o carbón vegetal por los habitantes de la comunidad; debiendo calcularse el volumen maderable para determinar los metros cúbicos de madera afectada (Castillo et al. (2018).

En este mismo contexto, Teutli-Hernández y Herrera-Silveira (2016) y Teutli-Hernández et al. (2020) señalan que para logar una restauración exitosa es necesario un diagnóstico apropiado y dar seguimiento y monitoreo a la zona intervenida, lo que permitirá al ecosistema crear condiciones favorables para su autorregeneración a través de una sucesión secundaria, logrando el restablecimiento aceptable de la hidrología y la vegetación con un periodo mínimo de dos años posteriores a la restauración, alcanzando su completa restauración hasta en un máximo de 17 años. De acuerdo con los resultados y las evidencias obtenidas, no se atendieron apropiadamente las recomendaciones metodológicas propuestas para esta zona de estudio.

Otro aspecto documentado fue la falta de involucramiento de toda la comunidad local, ya que su participación es fundamental en todo programa de restauración ecológica, tal como lo señalan Aronson et al. (2010) para que un proyecto sea exitoso. De hecho, además de considerar el aspecto ecológico, se debe contemplar la intervención comunitaria, así como la condición socioeconómica y cultural de la región, de tal manera que a la par de un proyecto de restauración 


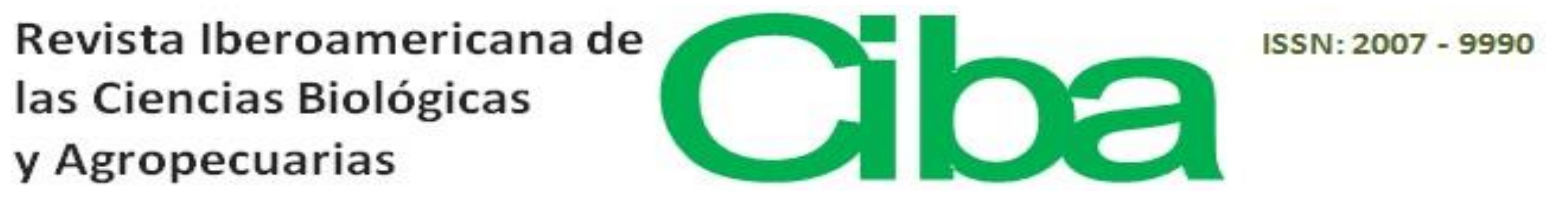

se genere alternadamente el impulso de proyectos productivos y compensatorios ambientales recomendados por la Comisión Nacional de Áreas Naturales Protegidas [Conanp] (2018) a través del Programa de Conservación para el Desarrollo Sostenible (Procodes), para optimizar la calidad de vida de los habitantes y las condiciones socioeconómicas de la región.

Otro elemento importante que se documentó fue que las autoridades gubernamentales de los niveles federal, estatal y local desconocían la intervención de restauración en el estero de Tila debido a la falta de coordinación entre autoridades y comunidad; en el caso de este estudio, la Conafor fue la institución gubernamental responsable de transparentar el programa federal financiado de compensación ambiental y dar el seguimiento, monitoreo y evaluación del área intervenida en esa zona de manglar; al respecto Vanegas (2016), señala la importancia de involucrar, socializar e informar sobre el procedimiento general de restauración ecológica fomentando la participación pública, considerándose una obligación dar a conocer públicamente los resultados de toda actividad de restauración, así como los indicadores de éxito favorables o desfavorables para correcciones futuras de los métodos y estrategias implementadas, con la finalidad de regular las acciones a través de la rendición de cuentas entre todos los actores involucrados.

Asimismo, Lindig y Zambrano (2007) y Teutli-Hernández y Herrera-Silveira (2016) explican que para asegurar el éxito en la restauración es necesario integrar a las comunidades locales para establecer conjuntamente la construcción de soluciones sostenibles que los beneficien directamente, desarrollando un plan de gestión comunitaria del manglar y capacitando a los habitantes en las diferentes técnicas de restauración a implementar, ya que ellos serán los que darán el seguimiento del sitio restaurado (Aronson et al., 2010), acciones que evidentemente no se implementaron en la restauración del estero de Tila, tal como lo mencionan los especialistas en el tema.

Por otro lado, quedó la evidencia de que no se cumplió con lo estipulado en la NOM-022SEMARNAT-2003, que establece las especificaciones para la preservación, conservación, aprovechamiento sustentable y restauración de los humedales costeros en zonas de manglar (Secretaría de Medio Ambiente y Recursos Naturales [Semarnat], 2003).

Finalmente, con base en los hallazgos obtenidos en el presente estudio, se determinó que no se siguió la correcta metodología propuesta para la restauración de la zona de manglar del estero de Tila; por lo tanto, es necesario profundizar en la revisión metodológico-científica que 
Revista Iberoamericana de las Ciencias Biológicas

y Agropecuarias

proporcione elementos técnicos adecuados para un correcto proceso de restauración ecológica de estos ecosistemas costeros.

\section{Conclusiones}

La intervención realizada en 2018 por la Conafor y algunos pobladores de la comunidad no obtuvo los resultados esperados en el proceso de restauración, lo cual fue confirmado por las evidencias obtenidas en 2020. Sin duda, la participación de la comunidad, las autoridades ambientales de los tres niveles de gobierno y los académicos especializados en el tema de restauración de manglar son fundamentales, ya que solo el trabajo colaborativo logrará el éxito deseado.

Por otro lado, fue evidente que para identificar los factores causantes de la mortandad de la vegetación de manglar no se siguió la metodología propuesta, con la cual se pueden evaluar los daños estructurales y funcionales de este ecosistema; por ello, son esenciales el seguimiento, monitoreo y la evaluación en la zona intervenida con la restauración.

Otro factor determinante para que no se llevara a cabo una restauración exitosa fue el seguimiento y supervisión por parte de las autoridades ambientales correspondientes, en este caso fue la Conafor la responsable de dar seguimiento al proceso de restauración ecológica, sin embargo, dos años después de la intervención en la zona de manglar, al buscar información relacionada con este estudio, las autoridades correspondientes desconocían la existencia de información referente al programa de restauración implementado en el estero de Tila.

Durante la realización del presente estudio, no se encontraron evidencias documentadas que sustentaran la realización de esta actividad de restauración, no se encontraron publicaciones científicas sobre los resultados, hallazgos, avances, monitoreo y evaluación del proceso de restauración sobre el área de estudio, lo cual son elementos indispensables para conocer el éxito o fracaso de la intervención, por lo que el presente estudio permitirá sentar las bases sobre el tema de restauración en zonas de manglar en el estado de Guerrero.

\section{Futuras líneas de investigación}

El presente diagnóstico desarrollado, se considera un referente para futuras investigaciones relacionadas con el proceso de restauración ecológica en zonas de manglar, debido a que hasta el momento en Guerrero no se cuenta con estudios científicos ni experiencias metodológicas que se 
hayan realizado exitosamente en el tema de restauración para estos ecosistemas costeros, de ahí la relevancia del presente estudio. Este diagnóstico, contempla las directrices metodológicas para una correcta intervención en áreas afectadas por actividades antropogénicas y/o fenómenos naturales que necesiten ser restauradas mediante la implementación de técnicas y métodos de restauración aplicables a zonas de manglar. Asimismo, este estudio es un parteaguas para futuras líneas de investigación en otros sitios con la misma problemática, ya que se contemplaron propuestas metodológicas y recomendaciones para una restauración exitosa que podrían ser aplicadas en otros sitios afectados.

Se consideran las siguientes líneas como referente para llevarlas a cabo en futuros estudios:

$\checkmark$ Identificar la problemática ambiental por actividades antropogénicas en las áreas de manglar y sus áreas anexas.

$\checkmark$ Determinar la importancia ecológica del manglar a través de la composición estructural, maderable, florística y faunística.

$\checkmark$ Implementar talleres participativos y acciones de difusión, concientización y educación ambiental entre los pobladores para el cuidado y protección de los ecosistemas de manglar.

$\checkmark$ Impulsar el establecimiento de viveros como Unidades de Manejo para la Conservación de Vida Silvestre (Umas) para la producción de plantas de mangle y contribuir a la conservación y forestación de las especies para generar alternativas de aprovechamiento integral sostenible en las comunidades anexas a las zonas de manglar.

\section{Agradecimiento}

Se agradece a la Procuraduría de Protección Ambiental del Estado de Guerrero (Propaeg) la invitación a participar en el diagnóstico y en el diseño de la propuesta metodológica para intervenir en la zona de manglar afectada, asimismo, por las facilidades otorgadas para el traslado al área afectada de manglares, a las autoridades Municipales de Marquelia, Guerrero, por el apoyo para los recorridos en campo. 
Revista lberoamericana de las Ciencias Biológicas

y Agropecuarias

\section{Referencias}

Aguilar-Garavito, M. y Ramírez, W. (eds.) (2015). Monitoreo a procesos de restauración ecológica, aplicado a ecosistemas terrestres. Instituto de Investigación de Recursos Biológicos Alexander von Humboldt (IAvH). Bogotá D. C., Colombia. Recuperado de http://repository.humboldt.org.co/bitstream/handle/20.500.11761/9281/monitoreo_restaurac ion_baja_1.pdf?sequence=1

Aronson, J., Blignaut, J. N, Milton, S. J, Le Maitre, D., Esler, K. J, Limouzin, A., Fontaine, C., De Wit, M. P, Mugido, W., Prinsloo, P., van der Elst, L. and Lederer, N. (2010). Are Socioeconomic Benefits of Restoration Adequately Quantified? A Meta-analysis of Recent Papers (2000-2008) in Restoration Ecology and 12 Other Scientific Journals. Restoration $\begin{array}{llll}\text { Ecology, } & 18(2), & \text { 143-154. } & \text { Retrieved }\end{array}$ http://lerf.eco.br/img/publicacoes/aronson_socioeconomic.pdf

Calderón, C., Aburto, O. y Ezcurra, E. (2009). El valor de los manglares. Biodiversitas, (82), 1-6 Recuperado de https://cesarjaro.files.wordpress.com/2013/04/manglares-art.pdf

Castillo, E. B, Gervacio J. H. y Bedolla S. R. (2018). Estructura forestal de una zona de manglar en la laguna de Coyuca de Benítez, Guerrero. Revista Mexicana de Ciencias Forestales, 9(45), 63-96. Recuperado de http://cienciasforestales.inifap.gob.mx/editorial/index.php/forestales/article/view/140

Castillo-Elías, B. y Gervacio-Jiménez, H. (2013). Evaluación preliminar de la presencia de plaga de palomilla Automeris spp (Saturniidae: Hemileucinae), en una zona de manglar en la Laguna de Nuxco, Guerrero. Foro de Estudios sobre Guerrero, 1(1), 383-385. Recuperado de

http://ri.uagro.mx/bitstream/handle/uagro/1282/15419_ART_2014.pdf?sequence=1\&isAllo wed $=\mathrm{y}$

Castillo-Elías, B., Gervacio-Jiménez, H., Bedolla-Solano, R., García-Domínguez, Y. B. y Mendoza-Almazán, E. (2017). Evaluación de la calidad del agua en el canal meándrico lagunar de Coyuca de Benítez, Gro. Revista Iberoamericana de Ciencias, 4(5), 57-69. Recuperado de http://www.reibci.org/publicados/2017/oct/2500111.pdf

Comín, A. F. (2014). Manual de restauración de humedales en cuencas agrícolas. España: Instituto Pirenaico de Ecología-CSIC. Editor: Comarca de Los Monegros. Recuperado de http://www.creamagua.com/documentos/Manual_humedales.pdf 
Revista Iberoamericana de las Ciencias Biológicas

y Agropecuarias

Comisión Nacional del Agua [Conagua] (2006). Estadísticas del Agua en México. Sistema Nacional de Información sobre cantidad, calidad, usos y conservación del agua (SINA) (4. ${ }^{\text {a }}$ ed.). México, D. F. Recuperado de http://www.conagua.gob.mx/CONAGUA07/Publicaciones/Publicaciones/eam_2006.pdf

Comisión Nacional de Áreas Naturales Protegidas [Conanp] (2018). Proyectos productivos, proyectos de vida. Programa de Conservación para el Desarrollo Sostenible (PROCODES). Recuperado de https://www.gob.mx/conanp/es/articulos/proyectos-productivos-proyectosde-vida?idiom $=$ es

Comisión Nacional Forestal [Conafor] (2009). La reforestación de los manglares en la costa de Oaxaca. Manual Comunitario. Zapopan, Jalisco, México. Recuperado de http://www.conafor.gob.mx/biblioteca/reforestacion-en-manglares-de-oaxaca.pdf

Comisión Nacional Forestal [Conafor] (2011). Recomendaciones para las actividades de restauración de manglares (3. ${ }^{\mathrm{a}}$ ed.). Coordinación General de Conservación y Restauración. Recuperado de http://www.conafor.gob.mx/biblioteca/Restauracion-de-manglares-2011.pdf Comisión Nacional Forestal y Secretaría de Medio Ambiente y Recursos Naturales [ConaforSemarnat]. (2010). Manual comunitario de restauración de manglares. Plan de acción regional para la restauración de los manglares de Nayarit. Nayarit, México. Recuperado de http://centro.paot.org.mx/documentos/conafor/MANUAL_COMUNITARIO.pdf

De la Lanza, E. G., Alcocer-Durand, J., Moreno-Ruiz, J. L. y Hernández-Pulido, S. P. (2008). Análisis químico-biológico para determinar el estatus trófico de la Laguna de Tres Palos Guerrero, México. Hidrobiológica, 18(1), 21-30. Recuperado de http://www.scielo.org.mx/pdf/hbio/v18n1/v18n1a3.pdf

Diego-Pérez, N. y Fonseca, R. M. (eds.) (2005). Flora de Guerrero. N. ${ }^{\circ}$ 22. Bataceae y Rhizophoraceae. Facultad de Ciencias, UNAM. Recuperado de http://biologia.fciencias.unam.mx/plantasvasculares/PDF\%20FLORAS/22\%20Bataceae\%2 0y\%20Rhizophoraceae.pdf

Dimas, M., Ortega, R. y Ortiz, D (2018). Calidad del agua de la laguna turística de Pie de la Cuesta. Revista Latinoamericana el Ambiente y las Ciencias, 9(21), 304-318. Recuperado de http://cmas.siu.buap.mx/portal_pprd/work/sites/rlac/resources/LocalContent/86/2/9(21)23.pdf 
Evans, K. A. y Guariguata, M. R. (2016). Éxito desde la base: el monitoreo participativo y la restauración de bosques. Documentos Ocasionales 167. Bogor, Indonesia: CIFOR. Recuperado de https://www.cifor.org/publications/pdf_files/OccPapers/OP-167.pdf

Ferrara-Guerrero, M. J., Castellanos-Páez, M. E. and Garza-Mouriño, G. (2007). Variation of a benthic heterotrophic bacteria community with different respiratory metabolisms in Coyuca de Benítez coastal lagoon (Guerrero, Mexico). Rev. Biol. Trop., 55(1), 157-169. Recuperado de https://www.scielo.sa.cr/pdf/rbt/v55n1/3615.pdf

Gann, G. D., Mc Donald, T., Walder, B., Aronson, J., Nelson, C. R., Jonson, J., Hallett J. G., Eisenberg, C., Guariguata, M. R., Liu, J., Hua, F., Echeverría, C., Gonzales E., Shaw, N., Decleer, K. and Dixon, K.W. (2019). International principles and standards for the practice of ecological restoration. Second edition. Restor Ecol, 27(S1), S1-S46. Doi: https://doi.org/10.1111/rec.13035

García-Domínguez, Y. B., Castillo-Elías, B., Sonder, K., Sampedro-Rosas, M. L., GervacioJiménez, H. and Bedolla-Solano, R. (2020). Environmental Impact on the Mangroves of the Municipality of Tecpan de Galeana, Guerrero, Mexico. International Journal of Applied Environmental Sciences, 15(2), 109-124. Retrieved from http://www.ripublication.com/ijaes20/ijaesv15n1_07.pdf

García-Domínguez, Y. B., Sampedro-Rosas, M. L., Castillo-Elias, B., Sonder, K., GervacioJiménez, H. and Bedolla-Solano, R. (2019). Community Management Plan for Sustainability of Mangrove Ecosystem in Nuxco Lagoon, Guerrero, Mexico. International Journal of Geography and Geology, 8(1), 10-20. Retrieved from de http://www.conscientiabeam.com/journal/10/abstract/5539

Gil, G., Violante, J. y Rojas, A. (2008). La producción pesquera de nueve especies comerciales en la laguna de Tres Palos, Gro., México. En Espino, B. E., Carrasco, M. Á., Fuentes, P., Cabral, E. G., Puente, M. y García, A. (eds.), Memorias del IV Foro Científico de Pesca Ribereña. (pp. 34-44). Recuperado de https://www.inapesca.gob.mx/portal/Publicaciones/Memorias/2008-IV-Foro-Cientifico-dePesca-Riberena-en-Acapulco.pdf?download

Gobierno del Estado de Guerrero (2015). Portal Oficial del Gobierno del Estado de Guerrero. Marquelia. Recuperado de http://guerrero.gob.mx/municipios/costa-chica/marquelia/ Gómez, B. S. (2012). Metodología de la investigación. Red Tercer Milenio S. C. Tlalnepantla, Estado de México.

Recuperado de 
Revista lberoamericana de las Ciencias Biológicas

y Agropecuarias

http://www.aliat.org.mx/BibliotecasDigitales/Axiologicas/Metodologia_de_la_investigacio n.pdf

González, G. T. (2008). El papel de la fotografía en la investigación cualitativa. El Ser Enfermero, 1(4), 5-9.

Google Earth Pro (2016). V 7.1.2.2600, DigitalGlobe 2016. Estero de Tila, Marquelia, Guerrero, México. $16^{\circ} 31^{\prime} 46,30^{\prime \prime} \mathrm{N}$ y $98^{\circ} 44^{\prime}$ 47,62" O, elevación 7 m.

Google Earth Pro. (2020). V 7.3.3.7721, DigitalGlobe 2020. Estero de Tila, Marquelia, Guerrero, México. $16^{\circ} 31^{\prime} 46,30^{\prime \prime} \mathrm{N}$ y $98^{\circ} 44^{\prime} 47,62 " \mathrm{O}$, Elevación 7 m.

Hernández-Sampieri, R., Fernández, C. C. y Baptista, L. P. (2018). Metodología de la Investigación (6. ${ }^{\mathrm{a}}$ ed.). Ciudad de México: Editorial Mc. Graw Hill.

Holl, K. D. and Aide, T. M. (2011). When and where to actively restore ecosystems? Forest Ecology and Management, 261, 1558-1563. Doi: https://doi.org/10.1016/j.foreco.2010.07.004

Instituto Nacional de Ecología [Ine]. (1989). Acuerdo CE-CCA-001/89. Por el que se establecen los criterios ecológicos de calidad del agua. Diario Oficial de la Federación. 2 de diciembre 1989. Recuperado de http://legismex.mty.itesm.mx/acu/acca001.pdf

Juárez, A., García, S., Olivier, S. B. y Zeferino, T. J. (2019). Producción primaria en manglar y su relación con variables fisicoquímicas del agua en Laguna Negra, Puerto Marques, Acapulco, Guerrero, México. Tlamati, 10(2), 27-40. Recuperado de http://www.tlamati.uagro.mx/t102/t1023.pdf

Lindig, C. R. y Zambrano, L. (2007). Aplicaciones prácticas para la conservación y restaruación de humedales y otros ecosistemas acuáticos. En Sánchez, O., Herzig, M., Peters, E., Márquez-Huitzil, R. y Zambrarno, Z. (eds.), Perspectivas sobre la conservación de ecosistemas acuáticos en México (pp. 167-188). Instituto Nacional de Ecología-Semarnat, U. S. Fish and Wildlife Service, Unidos para la Conservación. México. Recuperado de https://agua.org.mx/wp-content/uploads/2017/11/Perpectivas-sobre-conservaci\%C3\%B3nde-ecosistemas-acu\%C3\%A1ticos-en-M\%C3\%A9xico.pdf

Mitsch W. J. and Jørgensen, S. E. (2003). Ecological engineering: a field whose time has come. Ecological Engineering, 20(5), 363-377. Doi: https://doi.org/10.1016/j.ecoleng.2003.05.001 Monje, Á. C. A. (2011). Metodología de la investigación cuantitativa y cualitativa. Guía didáctica. Colombia. Recuperado de https://www.uv.mx/rmipe/files/2017/02/Guia-didacticametodologia-de-la-investigacion.pdf 
Revista lberoamericana de las Ciencias Biológicas

y Agropecuarias

Moreno-Casasola, P. y Peresbarbosa, E. (2006). Manejo integral de la zona costera. En Moreno-

Casasola, P., Peresbarbosa, E. y Travieso-Bello, A. C. (eds.), Estrategias para el manejo integral de la zona costera: un enfoque municipal (vol. I) (pp. 21-50). Instituto de Ecología A. C. y Comisión Nacional de Áreas Naturales Protegidas (SEMARNAT)-Gobierno del Estado de Veracruz. Xalapa.

Ochoa, G. S. (2010). Restauración ecológica: experiencias en México. En Vargas, G., Vargas, O., Rodríguez, A., Mollie Harker, C. y Monroy, A. S. (eds.). XVIII Congreso Mexicano de Botánica La Botánica Nacional en el Bicentenario de la Independencia (pp. 152-153). Guadalajara, Jalisco, México. Recuperado de http://www.conabio.gob.mx/institucion/proyectos/resultados/IU008_Anexo_Memorias.pdf Olguín, E. J., Hernández, M. E. y Sánchez-Galván, G. (2007). Contaminación de manglares por hidrocarburos y estrategias de biorremediación, fitorremediación y restauración. Rev. Int. Contam. Ambient, 23(3) 139-154. Recuperado de http://www.scielo.org.mx/pdf/rica/v23n3/v23n3a4.pdf

Perdomo, O. P., Miniño, V., Rodríguez de Francisco, L. y León, Y. (2018). Cytospora rhizophorae Kohlm and E. Kohlm (Valsaceae, Ascomycota) en la República Dominicana. Ciencia, Ambiente y Clima, 1(1), 23-31. Doi: https://doi.org/10.22206/cac.2018.v1i1

QGIS (2021). Equipo de Desarrollo. Quantum Geographic Information System. Sistema de Información Geográfica Quantum. Proyecto de Fundación Geoespacial de código abierto.

Ruiz-Ochoa, M. A., R. Meléndez, M., Castellanos y Polanía, J. (2006). Aplicación de medidas repetidas a cuatro propiedades edáficas en los manglares del brazo Calancala, río Ranchería. Rev. Acad. Colomb. Cienc., 30(115), 233-242. Recuperado de https://bit.ly/3u8rnvr

Secretaría de Medio Ambiente y Recursos Naturales [Semarnat] (2003). Norma Oficial Mexicana NOM-022-SEMARNAT-2003, que establece las especificaciones para la preservación, conservación, aprovechamiento sustentable y restauración de los humedales costeros en zonas de manglar. Publicada en el DOF el 10 de abril de 2003. Recuperado de http://www.profepa.gob.mx/innovaportal/file/3281/1/NOM-022-SEMARNAT-2003.pdf

Secretaría de Medio Ambiente y Recursos Naturales [Semarnat]. (2010). Norma Oficial Mexicana NOM-059-SEMARNAT-2010. Que determina las especies y subespecies de flora y fauna silvestres terrestres y acuáticas en peligro de extinción, amenazadas, raras y las sujetas a protección especial, y que establece especificaciones para su protección. Recuperado de https://biblioteca.semarnat.gob.mx/janium/Documentos/Ciga/agenda/DOFsr/DO2454.pdf 
Revista Iberoamericana de las Ciencias Biológicas

y Agropecuarias

Secretaría de Medio Ambiente, Recursos Naturales y Pesca-Instituto Nacional de Ecología [Semarnap-Ine]. (2000). La calidad del agua en los ecosistemas costeros de México. México, D. F. Recuperado de http://www.sct.gob.mx/fileadmin/CGPMM/biblioteca/ecologia/308.pdf Secretaría de Salud [Ssa]. (1994). Norma Oficial Mexicana NOM-127-SSA1-1994. Salud ambiental, agua para uso y consumo humano, límites permisibles de calidad y tratamientos a que debe someterse el agua para su potabilización. Diario Oficial de la Federación. 22 de noviembre de 2000. Recuperado de https://www.gob.mx/cms/uploads/attachment/file/110534/NOM_127_SSA1_1994.pdf

Secretaría de Salud [Ssa]. (2006). Método de prueba CCAYAC-M-004. Estimación de la densidad microbiana por la técnica del número más probable (NMP), detección de coliformes totales, coliformes fecales y escherichia coli por NMP. Diario Oficial de la Federación. 07 de marzo del 2006.

Society for Ecological Restoration [Ser]. (2004). Grupo de trabajo sobre ciencia y políticas. Principios de SER International sobre la restauración ecológica. Tucson: Society for Ecological Restoration International. Recuperado de https://cdn.ymaws.com/www.ser.org/resource/resmgr/custompages/publications/SER_Prim er/ser-primer-spanish.pdf

Taylor, S. J. y Bogdan, R. (2000). Introducción a los métodos cualitativos de investigación. Barcelona, España: Paidós. Recuperado de http://mastor.cl/blog/wpcontent/uploads/2011/12/Introduccion-a-metodos-cualitativos-de-investigaci\%C3\%B3nTaylor-y-Bogdan.-344-pags-pdf.pdf

Teutli-Hernández, C. y Herrera-Silveira, J. A. (2016). Capítulo 20: Estrategias de restauración de manglares de México: el caso Yucatán. En Ceccon, E. y Martínez-Garza (coords.), Experiencias mexicanas en la restauración de los ecosistemas (pp. 459-484). Universidad Nacional Autónoma de México, Centro Regional de Investigaciones Multidisciplinarias. Universidad Autónoma del Estado de Morelos, Comisión Nacional para el Conocimiento y Uso de la Biodiversidad. Recuperado de https://www.crim.unam.mx/web/sites/default/files/Experiencias\%20mexicanas.pdf

Teutli-Hernández, C., Herrera-Silveira, J. A., Cisneros de la Cruz, D. J. y Román-Cuesta, R. (2020). Guía para la restauración ecológica de manglares: lecciones aprendidas. Proyecto, Mainstreaming Wetlands into the Climate Agenda: A multi-level approach (SWAMP). CIFOR/CINVESTAV-IPN/UNAM-Sisal/PMC. 
Tovilla, H. y Orihuela, D. E. (2002). Floración, establecimiento de propágulos y supervivencia de Rizophora mangle L. en el manglar de Barra de Tecoanapa, Guerrero, México. Madera y Bosques (número especial), 89-102. Recuperado de https://myb.ojs.inecol.mx/index.php/myb/article/view/1293/1463

Vanegas, L. M. (2016). Manual de mejores prácticas de restauración de ecosistemas degradados, utilizando para reforestación solo especies nativas en zonas prioritarias. Informe final dentro del proyecto GEF 00089333 “Aumentar las capacidades de México para manejar especies exóticas invasoras a través de la implementación de la Estrategia Nacional de Especies Invasoras". CONAFOR, CONABIO, GEF-PNUD. México. Recuperado de https://procurement-notices.undp.org/view_file.cfm?doc_id=160946

Vences-Martínez, J. A., Sampedro-Rosas, M. L., Olmos-Martínez, E., Rosas-Guerrero, V., CatilloElías, B. and Juárez-López, A. L. (2018). Perception and Environmental Knowledge of anthropogenic activities in a coastal community. International Journal of Current Research, 10(3), 66750-66755. Recuperado de https://www.journalcra.com/sites/default/files/issuepdf/29170.pdf

Villerías, S., Tello, A. P. y García, N. (2016). Algunas características ambientales de la laguna de Tecomate, Guerrero, México. Tlamati, 7(1), 11-13. Recuperado de http://ri.uagro.mx/bitstream/handle/uagro/491/7136_ART2016_OK.pdf?sequence=1\&isAll owed $=\mathrm{y}$ 
Revista Iberoamericana de las Ciencias Biológicas y Agropecuarias

\begin{tabular}{|c|c|}
\hline Rol de Contribución & Autor (es) \\
\hline Conceptualización & Benjamín Castillo Elías (principal) \\
\hline Metodología & $\begin{array}{l}\text { Benjamín Castillo Elías (igual), Herlinda Gervacio Jiménez } \\
\text { (igual) }\end{array}$ \\
\hline Software & Benjamín Castillo Elías (principal) \\
\hline Validación & $\begin{array}{l}\text { Benjamín Castillo Elías (igual), Herlinda Gervacio Jiménez } \\
\text { (igual), José Angel Vences Martínez (igual) }\end{array}$ \\
\hline Análisis Formal & $\begin{array}{l}\text { Benjamín Castillo Elías (igual), Herlinda Gervacio Jiménez } \\
\text { (igual) }\end{array}$ \\
\hline Investigación & $\begin{array}{l}\text { Benjamín Castillo Elías (igual), Herlinda Gervacio Jiménez } \\
\text { (igual), José Angel Vences Martínez (igual) }\end{array}$ \\
\hline Recursos & $\begin{array}{l}\text { Benjamín Castillo Elías (principal), Herlinda Gervacio Jiménez } \\
\text { (igual), José Angel Vences Martínez (que apoya) }\end{array}$ \\
\hline Curación de datos & Benjamín Castillo Elías (principal) \\
\hline $\begin{array}{l}\text { Escritura - Preparación del } \\
\text { borrador original }\end{array}$ & $\begin{array}{l}\text { Benjamín Castillo Elías (principal), Herlinda Gervacio Jiménez } \\
\text { (igual), José Angel Vences Martínez (que apoya) }\end{array}$ \\
\hline $\begin{array}{l}\text { Escritura - Revisión y } \\
\text { edición }\end{array}$ & $\begin{array}{l}\text { Benjamín Castillo Elías (igual), Herlinda Gervacio Jiménez } \\
\text { (igual) }\end{array}$ \\
\hline Visualización & $\begin{array}{l}\text { Benjamín Castillo Elías (igual), Herlinda Gervacio Jiménez } \\
\text { (igual), José Angel Vences Martínez (que apoya) }\end{array}$ \\
\hline Supervisión & $\begin{array}{l}\text { Benjamín Castillo Elías (igual), Herlinda Gervacio Jiménez } \\
\text { (igual) }\end{array}$ \\
\hline Administración de Proyectos & $\begin{array}{l}\text { Benjamín Castillo Elías (igual), Herlinda Gervacio Jiménez } \\
\text { (igual), José Angel Vences Martínez (que apoya) }\end{array}$ \\
\hline Adquisición de fondos & $\begin{array}{l}\text { Benjamín Castillo Elías (igual), Herlinda Gervacio Jiménez } \\
\text { (igual), José Angel Vences Martínez (que apoya) }\end{array}$ \\
\hline
\end{tabular}

